\title{
Prospective measures of control and prevention of Helminthosis among agricultural animals in animal complexes
}

\author{
G.R. Bayramgulova, A.B. Zulkarnaev, S.M. Muzafarov, G.A. Yagafarova, and F.G. Aminev \\ Federal State Budgetary Educational Institution of Higher Education Bashkir State University, Sibay \\ Institute, Sibay, Russia
}

\begin{abstract}
Prospect of timely cleaning of livestock complexes from accumulated manure prevents environmental pollution. For this purpose, the most promising was the "cold" method of dehelminthization of a heap of manure, complete neutralization of chicken manure when heated and dried at temperatures above $100{ }^{\circ} \mathrm{C}$, a "dry" method for neutralizing horse, pig, cow, sheep manure from helminth eggs using the Kranz biothermal method. For dehelminthization of humans and animals, science has recommended, and practice has successfully tested a fairly large, constantly growing and updated range of highly effective anthelmintics, mainly for gastrointestinal and partially for pulmonary helminthiasis.
\end{abstract}

\section{Introduction}

At present, untimely cleaning of accumulated manure and, as a result, environmental pollution is a huge threat to the fate of any livestock complex. In this regard, the issue of the need to accelerate development of scientifically based recommendations for its removal and neutralization arises. Development of animal husbandry at the present stage requires cultivation of farm animals free from helminthiases, and creation of appropriate sanitary and epizootic conditions on the farms, which can be achieved through disinvasion and modernization of livestock complexes (Bayramgulova, 2010).

\section{Materials and Methods}

The subject of the study is a review of effective methods of dehelminthization of farm animals, devastation of the environment of the livestock complex. To study the methods of devastation of the environment of the livestock complex, we studied the range of highly effective anthelmintics, well-known disinfectants, methods of dehelminthization of the external environment, heaps of manure in livestock complexes.

\section{Results and Discussion}

When solving the problems of cleaning, storing and using manure in livestock complexes, the specific biological characteristics of eggs and larvae of helminths shall also be 
considered. Being thrown out with feces from the body of animals into the external environment, eggs and larvae of a number of helminth species for several days (in spring and summer) remain non-invasive, not dangerous for infecting animals with helminthiases. The eggs and larvae of many helminths of farm animals have the ability to stay in feces, manure and water for several days and only after that reach the invasive stage. Having reached invasiveness, they take root in the body of animals, undergo further development in them until maturity. In the invasive stage, the larvae and eggs of such helminths are unusually resistant to desiccation, insolation, changes in heat and cold. Human roundworm eggs, for example, remain in the garden soil for up to 7 years or more without losing their viability during all this time (Vasilkova, 1950).

Strongylid larvae of horses remain alive for months in shallow water bodies, and in hay - for up to a year (Velichkin, 1952). The larvae of trichostrongylidae and dictyocaulus of sheep and cattle remain viable from three months to a year (Romanenko et al., 2000). Considering the great sanitary and epizootological significance of the ecological features of human and animal helminths, the method of dehelminthization offered by K.I. Scryabin (1946) in1925 distinguished from the methods of conventional therapy, namely, by the fact that it requires to neutralize not only the helminths released from the body, but at the same time their eggs. Later, the same author recommended to call dehelminthization also all methods of neutralizing eggs and larvae of helminths in manure, on pastures, in water bodies, soil, water, premises where animals are kept, even on fruits, vegetables and various household items, by any means.

For dehelminthization of humans and animals, science has recommended, and practice has successfully tested a fairly large, constantly growing and updated range of highly effective anthelmintics, mainly for gastrointestinal and partially for pulmonary helminthiasis. Unfortunately, anthelmintics for dehelminthization in tissue helminthiasis (cysticercosis of cattle and reindeer, coenurosis of sheep, larval echinococcosis) are still unknown. However, a scientific search in this direction is still underway. There is reason to believe that it will probably also succeed. The offensive and defensive methods of prophylaxis used against tissue helminthiasis of animals (Skryabin, 1945) are complex, in some places difficult to carry out and, as a result, are not very effective.

Considering the above, in a number of foreign countries - England, France, Yugoslavia, Germany, Poland, Australia and New Zealand, a number of researchers are very successfully conducting experiments on active immunization of cattle, sheep and rabbits with cysticercosis.

In Australia and New Zealand, active immunization of sheep against cysticercosis is already being widely adopted in sheep farming. Simultaneously with foreign authors, immunization of cattle with cysticercosis began in Russia (Romanenko et al., 2000). With our participation, experiments in vaccination of sheep against coenurosis were laid in Kazakhstan. As a vaccine, oncospheres, artificially freed from embryophores obtained from mature segments of taeniidaes of dogs and humans are mainly used.

According to the results of immunization of animals with tissue helminthiasis obtained in Russia and abroad, we believe that the time has come to significantly expand and deepen scientific studies on this issue in our country by the efforts of both central and peripheral research helminthological institutes and laboratories, departments of parasitology of some veterinary institutes and faculties. A further delay in implementation of this kind of study will undoubtedly aggravate the lag of Russian helminthology on this issue from world science.

Reliable chemicals for dehelminthization of the external environment, especially manure in pig and livestock complexes, are still unknown. Emulsions and solutions of wellknown disinfectants widely used in practice - creolin, lysol, carbolic acid, bleach, mercuric chloride, and etc. - do not have a destructive effect on eggs and larvae of 
helminths (Skryabin, Petrov, 1964; Skryabin, Shultz, 1940; Velichkin, 1952). Even potassium cyanide does not kill Ascaris eggs (Zavadovsky, 1926). He explains this by presence of helminth eggs of an inner semipermeable lipoid membrane in the shell (Zavadovsky, 1915). It has been established that it is this that delays the permeability of solutions of disinfectants to embryos enclosed in eggs. The lipoid membrane is present in the shell, apparently, of helminth eggs of all types and classes. It was discovered by A. A. Skvortsov (1942) in the radial shell of oncospheres, A. A. Skvortsov (1936) - in an egg shell. R.S. Shultz and E.V. Gvozdev (1970), referring to the data of foreign authors, also indicate presence of a lipoid membrane in the structure of the embryophore of cestodes in general. According to M.M. Zavadovsky (1927), the lipoid membrane of the ascaris egg shell is destroyed by the action of fat-dissolving substances (gasoline, ether, acetone, chloroform, carbon tetrachloride), but alcohol does not penetrate through this membrane.

A.P. Markevich (1978) established that the lipoid membrane of the embryophore is shed from the oncosphere under the influence of intestinal juice on it with addition of bile, trypsin and some other agents.

Experimenting with eggs, K.I. Scryabin (1946) confirmed the data of other researchers that a $5 \%$ solution of carbolic acid heated to $55-60{ }^{\circ} \mathrm{C}$ causes the death of horse roundworm eggs, and water heated to the same temperature has a detrimental effect on the eggs of the same nematodes. Exposure to water with a temperature of 100,80 and $70{ }^{\circ} \mathrm{C}$ instantly kills the eggs of the horse roundworm. On this basis and the data of M.M. Zavidovsky and K.M. Sidorov (1926), VIGIS recommended a method for treating floors and walls in pigsties with boiling water, as well as cages for foxes and polar foxes (Skryabin, Petrov, 1964). However, in practice, this technique has not received wide recognition for a number of reasons: it is unsafe for performers, additionally humidifies the premises for pigs, and etc.

I.P. Gorshkov and E.E. Shumakovich (1935) used a "dry" method for neutralizing horse, pig, cow, sheep manure from helminth eggs using the Krantz biothermal method. With this method, manure is piled up on a layer of straw or dry neutralized manure in heaps, $1 \mathrm{~m}$ in size, loose to facilitate access to the manure for oxygen, and the top of the heap is covered with a layer of dry manure or soil. After a few days, horse or cow manure, pork manure mixed with horse manure, warms up under the influence of thermophilic microorganisms developing in it to a temperature of $55-60{ }^{\circ} \mathrm{C}$. Under the influence of this temperature, the germ cells in the eggs of helminths die. However, aerobic microorganisms are still viable. In order to neutralize them in the warmed-up manure is additionally compacted, as a result of which oxygen access to it ceases and the aerobic microflora dies.

With the "cold" method of dehelminthization, heaps of manure with a volume of $1 \mathrm{~m}$ are also tamped tightly when laying and in this state are kept for 15-20 days in spring and summer, and in winter - up to 1.5-2 months. During these periods, anaerobic conditions are created and maintained in the thickness of the manure, under which helminth eggs die. Currently, the anaerobic process is used in practice: animal husbandry - when keeping chickens and cattle on a permanent manure bed, and sheep - on a dung mattress. On cattle сатры, bases and in shed, sheep feces are simultaneously pass dehelminthization under the influence of sheep urine (Gorshkov, Shumakovich, 1935).

However, the rapid neutralization of manure is most desirable for livestock complexes, and for this purpose no other factor other than high temperature can be recommended. The experiments of S.P. Gusev (1939) in this direction made it possible to achieve complete neutralization of chicken manure when heated and dried at temperatures above $100{ }^{\circ} \mathrm{C}$. With this method of processing the chicken manure, a powdery mass that is safe for environmental pollution is formed, known as powder, a very valuable organic fertilizer and even a substance that can be used as feed for pigs and cattle. The powder contains $7-8 \%$ nitrogen, $4-5 \%$ phosphorus pentoxide, and $1-2 \%$ potassium oxide. At one of the poultry 
farms near Moscow (Gorshkov, Shumakovich, 1935), the preparation of powder by drying the chicken droppings at high temperatures is used not only as a method of disinfection and dehelminthization, but also as an economically useful product, the production of which provides arrangement of an industrial enterprise without harmful waste.

For almost 20 years in our country, methods of removing, storing, neutralizing and using manure in pig farms have been studied. However, unfortunately, no complete solutions have yet been found that would satisfy livestock complexes in all respects. As a result, hundreds of pig and livestock complexes are forced to continue to use artificial concrete sedimentation tanks for manure (Romanenko et al., 2000).

Such sedimentation tanks do not stand up to criticism in sanitary, epizootic, nature conservation and economic terms. The manure in the settling ponds remains open. It poisons the surrounding atmosphere with fetid gases. By attracting insects and birds to itself, manure becomes a source of dispersal of infections and infestations. For a long time spent in the settling tanks, manure loses organics valuable for fertilization.

\section{Conclusion}

Therefore, the prospect of using timely cleaning of livestock complexes from accumulated manure prevents environmental pollution. For this purpose, the most promising was the "cold" method of dehelminthization of a heap of manure, complete neutralization of chicken manure when heated and dried at temperatures above $100{ }^{\circ} \mathrm{C}$, a "dry" method for neutralizing horse, pig, cow, sheep manure from helminth eggs using the Kranz biothermal method. For dehelminthization of humans and animals, science has recommended, and practice has successfully tested a fairly large, constantly growing and updated range of highly effective anthelmintics, mainly for gastrointestinal and partially for pulmonary helminthiasis.

\section{References}

1. G. R. Bayramgulova, Bioecological aspects of epidemiology, epizootology, prevention of intestinal invasions of humans and animals in the Republic of Bashkortostan, 46 (2010)

2. Z. G. Vasilkova, Fundamentals of sanitary helminthology, 47 (1950)

3. P. A. Velichkin, The resistance of eggs and larvae of strongylids (delafondium, alfortium and trichonematine) to common disinfectants, 10, 77 (1952)

4. I. P. Gorshkov, E. E. Shumakovich, Methods for dehelminthization of farm animal manure, 1, 149 (1935)

5. M. M. Zavidovsky, K.M. Sidorov, Dependence of egg development on temperature. Tr. Labor experimental biol. of Moscow zoo, 3, 159 (1927)

6. N. A. Romanenko, I. K. Padchenko, N. V. Chebyshev, Sanitary parasitology, 354 (2000)

7. A. A. Skvortsov, Zool. magazine, 1-2, 10 (1942)

8. K. I. Skryabin, Total devastation - a new stage in improvement of humans and animals from helminthiases, 6 (1945)

9. K. I. Skryabin, Construction of Soviet helminthology, 211 (1946)

10. K. I. Skryabin, A. M. Petrov, Fundamentals of Veterinary Nematodology, 566 (1964)

11. K. I. Skryabin, R. S. Shults, Fundamentals of General Helminthology, 470 (1940)

12. R. S. Shults, E. V. Gvozdev, Fundamentals of General Helminthology, 1, 491 (1970) 